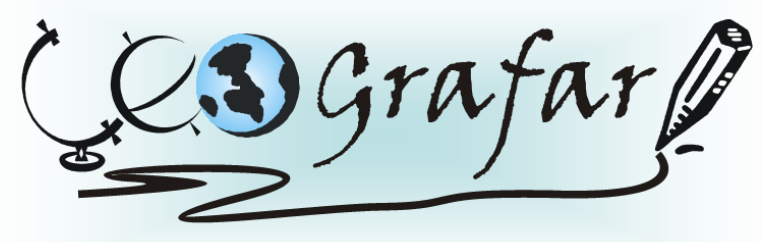

Revista Eletrônica do Programa de Pós-Graduação em Geografia - UFPR

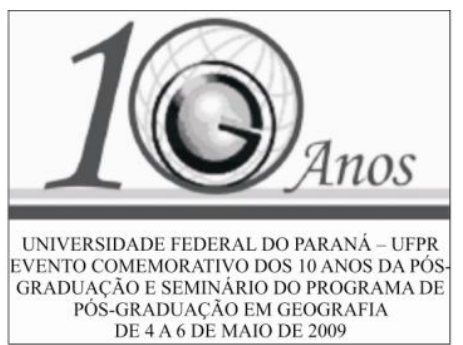

\title{
PLANEJAMENTO REGIONAL NO ESTADO DO PARANÁ A PARTIR DA DÉCADA DE 1990
}

\section{SONIA MAR DOS SANTOS MIGLIORINI ${ }^{1}$ LUIS LOPES DINIZ FILHO ${ }^{2}$}

\section{LINHA DE PESQUISA: PRODUÇÃO E TRANSFORMAÇÃO DO ESPAÇO URBANO- REGIONAL}

\section{INTRODUÇÃ̃O}

Após a crise da década de 1980 o planejamento regional no Brasil vem ganhando destaque entre as políticas governamentais. Com as profundas alterações que ocorreram nos modelos de desenvolvimento das atividades econômicas, a região passou a ser um instrumento importante para se planejar o desenvolvimento econômico.

O Brasil, atualmente, é marcado pelas agudas desigualdades regionais. Na realidade, segundo Galvão, o desenvolvimento econômico brasileiro "sempre teve feição regional". Algumas regiões do território nacional acabavam por se sobressair às demais, "angariando recursos humanos, materiais e financeiros e confirmando a percepção corrente de um país de vastas extensões de terras e relativa escassez de homens" (2003, p. 01).

O mesmo ocorre com o desenvolvimento regional do estado do Paraná, onde há grandes disparidades regionais e forte concentração da renda, emprego e dos meios de produção em determinadas regiões. No entanto, os governantes paranaenses, nos últimos anos, vêem se empenhados em desenvolver estudos regionais e planos de desenvolvimento econômico na tentativa de promover o desenvolvimento das regiões mais "atrasadas" do Estado.

Este trabalho refere-se ao projeto de pesquisa de doutorado da autora, iniciado em 2008, que investiga o planejamento regional no estado do Paraná a partir da década de 1990, através

\footnotetext{
${ }^{1}$ Doutoranda em Geografia pela Universidade Federal do Paraná. Email: snmigliorini@gmail.com

${ }^{2}$ Professor orientador
} 
do levantamento e análise dos planos governamentais desenvolvidos e implementados neste Estado.

\section{CONTEXTO E JUSTIFICATIVA}

A partir da década de 1990, o interesse pelas questões regionais, tanto no meio acadêmico como governamental, voltam a ter posição de destaque. Isso ocorreu exatamente em um momento em que o processo de integração e globalização da economia mundial parecia ter acabado com as diferenças existentes entre os lugares. No entanto, em vez da homogeneização do espaço, o que se evidenciou com a globalização foram as diferenças entres as regiões.

Arrais assinala que "a globalização não acabou com a especificidade, com o fragmento". Para o autor, o que a globalização trouxe de novo foi a visibilidade de certos lugares que ganharam importância com a revolução das tecnologias de informações. Desta forma, há poucos motivos para acreditar que a globalização seja um processo homogeneizador, de tal forma que se abre uma perspectiva fértil para pensarmos a região (2007, p. 42).

Para Diniz (2000, p.07), a globalização não elimina os contextos sociais e institucionais locais. Ao contrário, reforça a importância dos tecidos locais. Com as profundas alterações que ocorreram no modo de produzir nas décadas recentes, com modificações significativas nos modelos de desenvolvimento das atividades econômicas, a região tornou-se um importante instrumento de planejamento. É sabido que o conceito de região tem sido frequentemente empregado no decorrer da prática política e econômica de uma sociedade.

O Estado-Nacional, no seu processo de formação, centralizou os poderes econômicos e políticos. Intervir e planejar o território, considerando sua diversidade interna (cultura, economia, política, demografia, meio ambiente, etc.), esteve e está entre suas principais atribuições. "Primar pela unidade territorial significa, também, considerar a importância de sua diversidade, seja a partir do planejamento regional intervencionista ou mesmo pelo ato de regionalizar para fins administrativos, dividindo o país em regiões e sub-regiões" (ARRAIS, 2007, p.44). Desses dois pontos, nasceu a importância da região para o Estado.

Atualmente, a região tem se tornado uma importante categoria de análise para entender como o modo de produção capitalista se desenvolve em partes especificas de um determinado lugar (PERIS, 2002, p.21 e SANTOS, 1988, p. 47). 
O destaque dado aos temas regionais nos últimos anos, em nível nacional global e estadual, despertou-me o interesse em estudar o planejamento regional do estado do Paraná, pois, a partir da década de 1990, os órgãos governamentais do Estado têm desenvolvido estudos e planos de desenvolvimento regional com o objetivo de minimizar as disparidades econômicas existentes entre as regiões e alavancar o desenvolvimento das regiões mais “deprimidas". Contudo, na prática, observa-se que exatamente a partir da década de 1990 ocorreu uma forte concentração das atividades produtivas mais dinâmicas na região metropolitana do Estado, o que acabou por acentuar a desigualdade econômica entre as regiões. Diante disso, um estudo sobre os planos implementados a partir da década de 1990 e dos resultados desses planos é de grande importância para averiguar a eficiência desses no desenvolvimento das regiões bem como contribuição para diminuir as disparidades entre as regiões. Além disso, esse estudo contribuirá para o avanço das discussões teóricas sobre a questão regional e da eficiência dos planos governamentais de desenvolvimento regional.

\section{OBJETIVOS DA PESQUISA E METODOLOGIA}

A pesquisa parte do seguinte problema central: o governo brasileiro desde que deu início ao planejamento regional no País até o final da década de 1970 priorizou a criação de grandes planos de desenvolvimento regional, como o Plano de Metas de Juscelino Kubitschek e o I e II Plano Nacional de Desenvolvimento (PND), e investiu vultosos volumes de recursos públicos para a implementação destes planos. No entanto, com a crise da década de 1980 as atividades de planejamentos foram relegadas ao segundo plano. Os grandes planos de desenvolvimento regional brasileiro cederam espaço a medidas de curto prazo.

Nos anos de 1990, com a estabilização da economia, a atividade de planejamento volta a ocupar espaço, agora sob um novo paradigma no qual o Estado deixa de desenvolver grandes planos e passa a elaborar planos mais pontuais e de médio prazo. Além disso, o novo discurso inclui o desenvolvimento sustentável e as teorias da competitividade sistêmica. Neste novo modelo de planejar o desenvolvimento regional, o governo também deixa de bancar os custos do planejamento e passa a ser o mediador, atuando mais com políticas de incentivos fiscais de atração de capital, ou seja, a partir dos anos de 1990 o planejamento regional passa por uma renovação do discurso e ocorre um imobilismo do Estado.

Esta pesquisa busca averiguar até que ponto a mudança do discurso do planejamento regional pelo Estado teve algum resultado efetivo. Para isso será levantado e analisado os 
planos de desenvolvimento regional elaborados e implementados no estado do Paraná a partir da década de 1990, objetivando respondera as seguintes questões: quais dos planos de desenvolvimento regional elaborados para o estado do Paraná foram implementados de fato? de que forma foram implementados? quais foram os resultados dos planos implementados? e, através de indicadores econômicos, averiguar a eficácia das ações dos planos de desenvolvimento implementados no Estado.

A pesquisa será realizada essencialmente em duas etapas: na primeira será realizado um levantamento bibliográfico sobre estudos pertinentes ao tema da pesquisa e na segunda etapa será realizada uma entrevistas junto aos técnicos do IPARDES e da Secretaria de Estado do Planejamento e Coordenação Geral do estado do Paraná.

Palavras-chave: Novos paradigmas de planejamento, Planejamento regional, estado do Paraná,

\section{REFERÊNCIAS}

ARRAIS, T. P. A.. A Região como Arena Política: um estudo sobre a produção da região urbana centro-goiano. Goiânea: Série Ensaios, 2007.

DINIZ, C. C. Global-local: interdependências e desigualdades ou notas para uma política tecnológica e industrial regionalizadas no Brasil. Rio de Janeiro: UFRJ/IE, 2000.

GALVÃO A. F.. Política de Desenvolvimento Regional e Inovação: lições para o Brasil da experiência Européia. Campinas/SP, 2003.

PERIS, Alfredo Fonseca. Trilhas, Rodovias e Eixos: um estudo sobre desenvolvimento regional. Cascavel: Edunioeste, 2002.

SANTOS, Milton. Metamorfoses do Espaço Habitado. São Paulo: Hucitec, 1988. 